\title{
Validation of the scale on Satisfaction of Adolescents with Postoperative pain management - idiopathic Scoliosis (SAP-S)
}

This article was published in the following Dove Press journal: Journal of Pain Research

II January 2017

Number of times this article has been viewed

\author{
Christelle Khadra ${ }^{1-3}$ \\ Sylvie Le May',2 \\ Ariane Ballard 1,2 \\ Jean Théroux ${ }^{1,4}$ \\ Sylvie Charette ${ }^{5}$ \\ Edith Villeneuve ${ }^{6,7}$ \\ Stefan Parent $2,8,9$ \\ Argerie Tsimicalis ${ }^{10,11}$ \\ Jill MacLaren Chorney ${ }^{12,13}$
}

'Faculty of Nursing, Université de Montréal, ${ }^{2} \mathrm{CHU}$ Sainte-Justine Research Centre, ${ }^{3}$ Montreal Chest Institute, McGill University Health Centre, Montreal, QC, Canada; ${ }^{4}$ School of Health Professions, Murdoch University, Perth, WA, Australia; ${ }^{5}$ Direction of Nursing, ${ }^{6}$ Department of Anesthesia, CHU Sainte-Justine, ${ }^{7}$ Department of Anesthesia, ${ }^{8}$ Department of Surgery, Faculty of Medicine, Université de Montréal, ' Orthopaedic Service, Department of Surgery, CHU SainteJustine, ${ }^{10}$ Ingram School of Nursing, McGill University, "Shriners Hospitals for Children, Montreal, QC, ${ }^{12}$ Pediatric Complex Pain Team, IWK Health

Centre, ${ }^{13}$ Department of Anesthesia, Pain Management, and Perioperative Medicine, Faculty of Medicine, Dalhousie University, Halifax, NS, Canada

Correspondence: Sylvie Le May Faculty of Nursing, Université de Montréal, PO Box 6128, Succursale Centre-Ville, Montreal, QC, Canada $\mathrm{H} 3 \mathrm{C} 3 \mathrm{~J} 7$

Tel +I 5145668892

$\mathrm{Fax}+|45062| 3960$

Email sylvie.lemay@umontreal.ca
Background: Spinal fusion is a common orthopedic surgery in children and adolescents and is associated with high pain levels postoperatively. If the pain is not well managed, negative outcomes may ensue. To our knowledge, there is no measure in English that assesses patient's satisfaction with postoperative pain management following idiopathic scoliosis surgery. The aim of the present study was to assess the psychometric properties of the satisfaction subscale of the English version of the Satisfaction of Adolescents with Postoperative pain management idiopathic Scoliosis (SAP-S) scale.

Methods: Eighty-two participants aged 10-18 years, who had undergone spinal fusion surgery, fully completed the SAP-S scale at 10-14 days postdischarge. Construct validity was assessed through a principal component analysis using varimax rotation.

Results: Principal component analysis indicated a three-factor structure of the 13-item satisfaction subscale of the SAP-S scale. Factors referred to satisfaction regarding current medication received (Factor 1), actions taken by nurses and doctors to manage pain (Factor 2) and information received after surgery (Factor 3 ). Cronbach's alpha was 0.91 , showing very good internal consistency. Data on satisfaction and clinical outcomes were also reported.

Conclusion: The SAP-S is a valid and reliable measure of satisfaction with postoperative pain management that can be used in both research and clinical settings to improve pain management practices. Although it was developed and validated with adolescents who had undergone spinal fusion surgery, it can be used, with further validation, to assess adolescents' satisfaction with pain management in other postoperative contexts.

Keywords: satisfaction, pain management, adolescents, scoliosis, orthopedics, postoperative pain

\section{Introduction}

Every year, thousands of children younger than 18 years of age undergo surgery in Canada, averaging 64,000 per year, ${ }^{1}$ with the numbers reaching and exceeding half a million in the US ${ }^{2}$ and in the UK. ${ }^{3}$ Pain is a symptom commonly experienced following surgery due to tissue damage. ${ }^{4}$ Idiopathic scoliosis surgery (posterior spinal fusion), a common orthopedic surgery in children and adolescents, is a surgical procedure to correct spinal deformities, which generates high levels of pain. ${ }^{5}$ This major invasive surgical procedure entails considerable nociceptive input in a highly innervated area, rendering the pain assessment and management an important challenge for clinicians and patients postoperatively. ${ }^{6,7}$

Inadequate postoperative pain relief can lead to negative psychological and physiological outcomes, with children undergoing orthopedic surgery remaining particularly 
vulnerable. ${ }^{8}$ Postoperative pain may delay recovery and rehabilitation, ${ }^{9}$ delay ambulation ${ }^{10,11}$ and increase the risk of vomiting and sleep disturbances ${ }^{12}$ as well as persistent post-surgical pain. ${ }^{13-15}$ Furthermore, pain management is an important predictor of patients' overall satisfaction with the quality of care. ${ }^{16}$

Patient satisfaction is often considered an indicator of the quality of care and used as a proxy to measure the hospitals' and the clinicians' success in delivering a timely and efficient patient-centered care. ${ }^{17,18}$ It has gained more attention in recent years as many countries such as the US and the UK offer incentives for physicians to reach quality targets. ${ }^{17}$ This is because patients' satisfaction impacts clinical outcomes, financial gains, patient retention, reimbursement rates and malpractice claims. ${ }^{18,19}$ The Agency for Healthcare Research and Quality (AHRQ) recognizes pain management as an obligation and part of the health care professionals' commitment toward their patients. ${ }^{20}$ Effective pain management is also positively associated with patient satisfaction. ${ }^{21}$ Furthermore, a survey found a strong correlation between patient satisfaction and the perception that health care professionals did everything they could to control their pain. ${ }^{22}$

With the growing need of the health care system to optimize patients' experiences, ${ }^{13}$ there is an urgent need for welldesigned and appropriately administered patient satisfaction measures. ${ }^{23}$ To our knowledge, there is no measure that assesses adolescents' satisfaction with postoperative pain management following posterior spinal fusion for idiopathic scoliosis. Currently, the 30-item Scoliosis Patient Questionnaire (SPQ) ${ }^{24}$ of the Scoliosis Research Society (SRS), previously SRS 22, 23 and 24 , is the most commonly used measure for health-related quality of life in adolescents with idiopathic scoliosis before and after surgery. The $\mathrm{SPQ}^{24}$ includes six items to assess pain intensity and analgesic use, but only one item concerns the postoperative period and no items are specifically related to the quality of postoperative pain care and management, which is imperative for improving quality of care and optimizing patients' experiences. ${ }^{25}$ Hence, the aim of this study was to evaluate the psychometric properties of the satisfaction subscale of the Satisfaction of Adolescents with Postoperative pain management - idiopathic Scoliosis (SAP-S) scale (English version) (Supplementary material) ${ }^{26}$ This measure was initially developed and validated in French by Ballard et al (unpublished data, 2016) with the same population of adolescents, but has yet to be translated and validated in English.

\section{Methods}

\section{Study design and setting}

This study was nested within a multisite study, called PostOperative Recovery following Spinal Correction: Home
Experience (PORSCHE), aimed to address the prevalence, predictors and consequences of children's pain following major surgery. One of the coauthors (JMC) received a grant from the Canadian Institutes of Health Research for the PORSCHE study (201003MOP-221958-CHIIWKI-192333). The following university-affiliated, adult and pediatric hospitals served as the study settings: the IWK Health Centre (Halifax, NS, Canada), Saint John Regional Hospital (Saint John, NB, Canada), McGill University Health Centre (Montreal, QC, Canada), McMaster University Medical Centre (Hamilton, ON, Canada), the Children's Hospital of Eastern Ontario (Ottawa, ON, Canada), CHU Sainte-Justine (Montreal, QC, Canada) and Alberta Children's Hospital (Calgary, AB, Canada). The study was initially approved by the IWK Health Centre Research Ethics and Review Board and received another review by each participating site.

\section{Participants}

Participants eligible for the instrument validation study included those who fully completed the SAP-S scale (English version; $\mathrm{n}=82$ ) among the participants in the PORSCHE study $(n=249)$. Participants were eligible for the PORSCHE study if they were: 1) between 10 and 18 years of age; 2) scheduled to undergo a spinal fusion with instrumentation for adolescent idiopathic scoliosis and 3) accompanied by one parent. Potential participants were excluded if: 1) the child and parent were unable to speak or read English adequately to complete the study measures; 2) if the child had a significant developmental delay or intellectual disability (as the measures have not been validated for these groups) and 3) if the child had any major chronic medical conditions (American Society of Anesthesiologists (ASA) physical status III or higher). The sample size for the satisfaction subscale validation study was guided by the "rule of thumb", which stipulates that 5-10 participants are needed per item to perform analyses for validation. ${ }^{27}$ The anticipated psychometric analysis entailed the validation of 13 items; thus, the minimum requirement was 65 participants. Hence, the sample size of 82 participants was considered sufficient for validation.

\section{Recruitment and procedures}

Initial recruitment into the PORSCHE study consisted of potential participants being identified and informed of the study by their attending surgeon during a surgical consult. If parent(s) expressed an interest in hearing more about the study, they were directed to a research assistant who provided information about the study via the information and consent form. Recruitment procedures varied slightly by site, with 
potential participants either providing consent at the time of this visit or being called at home 2-3 weeks after the visit. After obtaining written assents from all of the participating adolescents and written informed consents from all of their parent(s) or legal guardian(s), participants received a baseline questionnaire package by postal mail requesting them to complete and return it by mail before the day of surgery. At 10-14 days postdischarge, participants were mailed the SAP-S scale. Upon receipt of each questionnaire package, participants were mailed a gift card.

\section{Instrument on SAP-S}

The SAP-S is a measure designed to evaluate satisfaction with postoperative pain management of adolescents undergoing spinal fusion for idiopathic scoliosis. The measure was initially developed and validated in French at a university-affiliated pediatric hospital in Montreal, Canada. The French validation of the section B subscale on satisfaction showed good internal consistency with a Cronbach's alpha of 0.82 (Ballard et al, unpublished data, 2016). The English version underwent a forward translation (from French to English by a translator specialized in health care), followed by a back translation (by a bilingual expert panel of nurse clinicians specialized in orthopedic surgery; back-to-back translation), resulting in a high correlation (0.92) between the two translated English versions. The SAP-S scale (English version), presented in the Supplementary material, consists of six sections from A to F. Section A is where the participant indicates the date of the surgery and the exact date at which they filled out the scale. Section B requires the adolescents to rate their level of satisfaction with pain management and the information they received about pain management and recovery during hospitalization as well as the importance of each statement on a 6-point scale ranging from 1 (least satisfied/least important) to 6 (very satisfied/ very important). In section $\mathrm{C}$, participants were asked to report each related side effect they might have experienced and its unpleasantness on a 10-point scale from 1 (not at all) to 10 (very much). In section $\mathrm{D}$, participants are asked to rate their satisfaction with the drug delivery (medication format) by circling a number from 1 (least satisfied) to 6 (very satisfied) for each option. Section E includes items about the current level of pain, the worst pain experienced during the last week, and the most frequent pain intensity felt in the past week on a Numeric Pain Rating Scale ranging from 0 (absence of pain) to 10 (worst pain felt). Section $F$ includes open-ended questions where patients were able to express what were the most and least helpful aspects regarding their pain management during hospitalization.

\section{Psychometric tests and statistical methods}

Psychometric testing of the SAP-S was conducted to validate the 13-item satisfaction subscale (section B) because the other sections were not amenable for this type of analyses. Construct validity was assessed through a principal component analysis (PCA) using varimax rotation. The Kaiser-Meyer-Olkin (KMO) measure of sampling adequacy and the Bartlett's test of sphericity were conducted prior to running the analysis. Inter-item correlations were calculated to compare correlations between all 13 pairs of items. Cronbach's alpha was calculated as a measure of the scale's internal consistency with a minimally accepted level of $0.70 .{ }^{28}$ Descriptive statistics were used to describe the sample characteristics and to report clinical data and satisfaction as well as item importance ratings derived from the SAP-S measure. Analyses were conducted using IBM ${ }^{\circledR}$ SPSS $^{\circledR}$ Statistics, version 24.

\section{Results}

Among the 249 subjects who participated in the PORSCHE Study, only 163 were English speaking. Among those, only 82 fully completed the SAP-S scale and were therefore included in the analysis.

\section{Sample characteristics}

Overall, 82 adolescents with a mean age of 14.6 years ( \pm 1.8 years) and mainly girls $(81 \%)$ completed the SAP-S scale (English version), following a spinal fusion for idiopathic scoliosis. Participants were hospitalized for $\sim 6$ days (5.9 \pm 1.4 days). Participants received pharmacological pain management according to the site's protocol and were followed by Pain Services as per standard of care. Pain medication included but was not limited to morphine, hydromorphone, oxycodone or fentanyl. The doses and routes of administration differed from one site to another depending on the protocol in place.

\section{Construct validity}

Prior to conducting the PCA, the KMO and Bartlett's test were calculated. For the analysis to be suitable, the KMO index should be $>0.50$ and the Bartlett's test of sphericity should be significant $(p<0.05)$. For the present study, the calculated KMO was 0.861 and the Bartlett's test result was $p<0.000$. PCA results indicated a three-factor structure of the 13-item satisfaction subscale of the SAP-S scale. The three-factor structure was also confirmed by the scree plot of the eigenvalues (Figure 1). The factor structure referred to satisfaction regarding current medication received (Factor 1), actions taken by nurses and doctors to manage pain (Factor 2) and information received after surgery (Factor 3 ). Item 2 regarding satisfaction with 


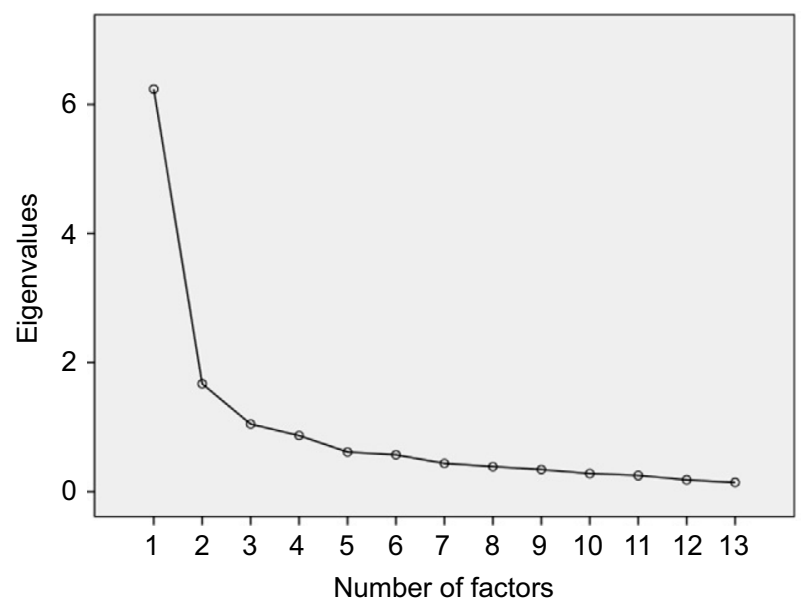

Figure I Scree plot to determine the number of factors to retain. "the information about medication used to reduce pain" was added to Factor 3 as it loaded (0.497) nearly as much as it did on Factor 1 (0.531) and the content of the item was more related to Factor 3. The three factors explained $68.88 \%$ of the variance (Factor 1: $47.989 \%$, Factor 2: $12.855 \%$ and Factor 3: $8.036 \%$ ). Detailed results are presented in Table 1 .

\section{Internal consistency}

Cronbach's alpha for the 13-item satisfaction scale of the SAP-S was 0.91 . Only one item regarding satisfaction with the information received about the side effects of pain medication could have yielded a slightly higher Cronbach's alpha if deleted (0.911). The majority of items on the inter-item correlation matrix had good correlations $(>0.3$; Table 2$)$.

Table I Factor loadings from principal component analysis with varimax rotation

\begin{tabular}{|c|c|c|c|}
\hline \multirow[t]{2}{*}{ Items } & \multicolumn{3}{|c|}{ Factors } \\
\hline & $\mathbf{I}$ & 2 & 3 \\
\hline Item 12: The amount of pain relief the medication brings you & 0.896 & 0.137 & 0.146 \\
\hline Item 13: The duration of pain relief the medication brings you & 0.862 & 0.194 & 0.219 \\
\hline Item II: The length of time the medication takes before relieving the pain & 0.823 & 0.185 & 0.104 \\
\hline Item 5: The information about medications used when returning home and their side effects & 0.693 & 0.291 & 0.194 \\
\hline Item 2: The information about medication used to reduce pain & 0.531 & 0.230 & 0.497 \\
\hline Item 9: Asking you about your pain level on a scale of $\mathrm{I}-10$, every morning, afternoon and evening & 0.061 & 0.797 & 0.335 \\
\hline Item 8: Asking you questions about pain you are feeling when you breathe deeply, when you sit or when you move around & 0.166 & 0.780 & 0.356 \\
\hline Item 3: The information about the way to measure pain with a pain scale & 0.142 & $0.7 \mathrm{II}$ & -0.042 \\
\hline Item 7: Helping you find a comfortable position in your bed in order to reduce pain & 0.405 & 0.677 & -0.003 \\
\hline Item 10: Treating your pain until its relieved & 0.357 & 0.664 & 0.337 \\
\hline Item 6: Believing you when you talk to them about your pain & 0.225 & 0.653 & 0.372 \\
\hline Item 4: The information about side effects you could have (eg, nausea, itching, etc) & 0.180 & 0.110 & 0.842 \\
\hline Item I: The information about the intensity of pain & 0.191 & 0.305 & 0.728 \\
\hline
\end{tabular}

Notes: Bold is used to indicate significant loading of items. Factor I: satisfaction regarding current medication received. Factor 2: satisfaction with postoperative pain actions taken by nurses and doctors to manage pain. Factor 3: management and information received after surgery.

Table 2 Inter-item correlation matrix for satisfaction subscale

\begin{tabular}{|c|c|c|c|c|c|c|c|c|c|c|c|c|c|}
\hline & Item I & Item 2 & Item 3 & Item 4 & Item 5 & Item 6 & Item 7 & Item 8 & Item 9 & Item I0 & Item I I & Item I 2 & Item 13 \\
\hline Item I & 1.000 & 0.432 & 0.210 & 0.479 & 0.236 & 0.557 & 0.308 & 0.474 & 0.488 & 0.463 & 0.342 & 0.313 & 0.399 \\
\hline Item 2 & 0.432 & 1.000 & 0.178 & 0.455 & 0.469 & 0.377 & 0.377 & 0.465 & 0.350 & 0.562 & 0.460 & 0.535 & 0.524 \\
\hline Item 3 & 0.210 & 0.178 & 1.000 & 0.154 & 0.203 & 0.455 & 0.392 & $0.48 I$ & 0.640 & 0.464 & 0.260 & 0.310 & 0.353 \\
\hline Item 4 & 0.479 & 0.455 & 0.154 & 1.000 & 0.407 & 0.355 & 0.188 & 0.451 & 0.379 & 0.345 & 0.270 & 0.346 & 0.353 \\
\hline Item 5 & 0.236 & 0.469 & 0.203 & 0.407 & 1.000 & 0.339 & 0.545 & 0.412 & 0.344 & 0.397 & 0.531 & 0.588 & 0.631 \\
\hline Item 6 & 0.557 & 0.377 & 0.455 & 0.355 & 0.339 & 1.000 & 0.526 & 0.604 & 0.559 & 0.644 & 0.494 & 0.457 & 0.468 \\
\hline Item 7 & 0.308 & 0.377 & 0.392 & 0.188 & 0.545 & 0.526 & 1.000 & 0.659 & 0.542 & 0.495 & 0.479 & 0.459 & $0.4 I I$ \\
\hline Item 8 & 0.474 & 0.465 & $0.48 I$ & 0.451 & 0.412 & 0.604 & 0.659 & 1.000 & 0.752 & 0.593 & 0.357 & 0.415 & 0.431 \\
\hline Item 9 & 0.488 & 0.350 & 0.640 & 0.379 & 0.344 & 0.559 & 0.542 & 0.752 & 1.000 & 0.622 & 0.296 & 0.298 & 0.361 \\
\hline Item 10 & 0.463 & 0.562 & 0.464 & 0.345 & 0.397 & 0.644 & 0.495 & 0.593 & 0.622 & 1.000 & 0.461 & 0.544 & 0.589 \\
\hline Item II & 0.342 & 0.460 & 0.260 & 0.270 & 0.531 & 0.494 & 0.479 & 0.357 & 0.296 & 0.461 & 1.000 & 0.737 & 0.740 \\
\hline Item 12 & 0.313 & 0.535 & 0.310 & 0.346 & 0.588 & 0.457 & 0.459 & 0.415 & 0.298 & 0.544 & 0.737 & 1.000 & 0.808 \\
\hline Item 13 & 0.399 & 0.524 & 0.353 & 0.353 & 0.631 & 0.468 & $0.4 I I$ & 0.431 & $0.36 \mathrm{I}$ & 0.589 & 0.740 & 0.808 & 1.000 \\
\hline
\end{tabular}

Notes: Item I: The information about the intensity of pain. Item 2: The information about medication used to reduce pain. Item 3: The information about the way to measure pain with a pain scale. Item 4: The information about side effects you could have (eg, nausea, itching, etc). Item 5: The information about medications used when returning home and their side effects. Item 6: Believing you when you talk to them about your pain. Item 7: Helping you find a comfortable position in your bed in order to reduce pain. Item 8: Asking you questions about pain you are feeling when you breathe deeply, when you sit or when you move around. Item 9: Asking you about your pain level on a scale of I to 10, every morning, afternoon and evening. Item 10: Treating your pain until its relieved. Item II: The length of time the medication takes before relieving the pain. Item 12: The amount of pain relief the medication brings you. Item I3: The duration of pain relief the medication brings you. 


\section{Satisfaction with postoperative pain management}

Participants in the study were satisfied with all aspects of postoperative pain management with an overall mean rating of $4.6( \pm 0.9)$ out of 6 for all 13 items. On average, participants were mostly satisfied with Item 6 referring to nurses and doctors "Believing you when you talked to them about your pain" (5.0 \pm 1.2$)$, while they were least satisfied with Item 4 "The information about side effects you could have (eg, nausea, itching, etc)" (4.0 \pm 1.5$)$. Detailed results are presented in Table 3.

\section{Item importance ratings}

All items were evaluated as important to very important with an overall mean of $4.9( \pm 0.7)$ out of 6 (Table 4$)$. The three most important items according to participants were all related to actions taken by nurses and doctors for pain management: 1) "Helping you find a comfortable position in your bed in order to reduce pain" $(5.5 \pm 0.7) ; 2)$ "Believing you when you talked to them about your pain" (5.5 \pm 0.8$)$ and 3$)$ "Treating your pain

Table 3 Satisfaction with postoperative pain management

\begin{tabular}{|c|c|}
\hline Items of the SAP-S satisfaction subscale* & $\begin{array}{l}\text { Mean satisfaction } \\
(\text { mean } \pm \text { SD) }\end{array}$ \\
\hline $\begin{array}{l}\text { Item I: The information about the intensity } \\
\text { of pain }\end{array}$ & $4.5 \pm 1.2$ \\
\hline $\begin{array}{l}\text { Item 2: The information about medication used } \\
\text { to reduce pain }\end{array}$ & $4.5 \pm 1.2$ \\
\hline $\begin{array}{l}\text { Item 3: The information about the way to } \\
\text { measure pain with a pain scale }\end{array}$ & $4.5 \pm 1.3$ \\
\hline $\begin{array}{l}\text { Item 4: The information about side effects you } \\
\text { could have (eg, nausea, itching, etc) }\end{array}$ & $4.0 \pm 1.5$ \\
\hline $\begin{array}{l}\text { Item 5: The information about medications used } \\
\text { when returning home and their side effects }\end{array}$ & $4.5 \pm 1.4$ \\
\hline $\begin{array}{l}\text { Item 6: Believing you when you talk to them } \\
\text { about your pain }\end{array}$ & $5.0 \pm 1.2$ \\
\hline $\begin{array}{l}\text { Item 7: Helping you find a comfortable position } \\
\text { in your bed in order to reduce pain }\end{array}$ & $4.9 \pm 1.2$ \\
\hline $\begin{array}{l}\text { Item 8: Asking you questions about pain you } \\
\text { are feeling when you breathe deeply, when you } \\
\text { sit or when you moved around }\end{array}$ & $4.6 \pm 1.2$ \\
\hline $\begin{array}{l}\text { Item 9: Asking you about your pain level on } \\
\text { a scale of } \mathrm{I}-10 \text {, every morning, afternoon } \\
\text { and evening }\end{array}$ & $4.7 \pm 1.2$ \\
\hline Item 10: Treating your pain until it is relieved & $4.7 \pm 1.4$ \\
\hline $\begin{array}{l}\text { Item II: The length of time the medication } \\
\text { takes before relieving the pain }\end{array}$ & $4.4 \pm 1.2$ \\
\hline $\begin{array}{l}\text { Item 12: The amount of pain relief the } \\
\text { medication brings you }\end{array}$ & $4.6 \pm 1.1$ \\
\hline $\begin{array}{l}\text { Item 13: The duration of pain relief the } \\
\text { medication brings you }\end{array}$ & $4.5 \pm 1.2$ \\
\hline Overall mean & $4.6 \pm 0.9$ \\
\hline
\end{tabular}

Note: *Results on a 6-point Likert-type scale for satisfaction (minimum = I: least satisfied; maximum $=6$ : very satisfied).

Abbreviation: SAP-S, Satisfaction of Adolescents with Postoperative pain management - idiopathic Scoliosis.
Table 4 Item importance rating

\begin{tabular}{|c|c|}
\hline Items of the SAP-S satisfaction subscale & $\begin{array}{l}\text { Mean importance } \\
\text { (mean } \pm \text { SD) }\end{array}$ \\
\hline $\begin{array}{l}\text { Item I: The information about the intensity } \\
\text { of pain }\end{array}$ & $4.5 \pm 1.2$ \\
\hline $\begin{array}{l}\text { Item 2: The information about medication used } \\
\text { to reduce pain }\end{array}$ & $4.9 \pm 1.4$ \\
\hline $\begin{array}{l}\text { Item 3: The information about the way to } \\
\text { measure pain with a pain scale }\end{array}$ & $3.9 \pm 1.4$ \\
\hline $\begin{array}{l}\text { Item 4: The information about side effects you } \\
\text { could have (eg, nausea, itching, etc) }\end{array}$ & $4.3 \pm 1.4$ \\
\hline $\begin{array}{l}\text { Item 5: The information about medications used } \\
\text { when returning home and their side effects }\end{array}$ & $4.7 \pm 1.2$ \\
\hline $\begin{array}{l}\text { Item 6: Believing you when you talk to them } \\
\text { about your pain }\end{array}$ & $5.5 \pm 0.8$ \\
\hline $\begin{array}{l}\text { Item 7: Helping you find a comfortable position } \\
\text { in your bed in order to reduce pain }\end{array}$ & $5.5 \pm 0.7$ \\
\hline $\begin{array}{l}\text { Item 8: Asking you questions about pain you are } \\
\text { feeling when you breathe deeply, when you sit } \\
\text { or when you moved around }\end{array}$ & $4.8 \pm 1.2$ \\
\hline $\begin{array}{l}\text { Item 9: Asking you about your pain level on } \\
\text { a scale of } 1-10 \text {, every morning, afternoon } \\
\text { and evening }\end{array}$ & $4.5 \pm 1.5$ \\
\hline Item 10: Treating your pain until it is relieved & $5.5 \pm 0.8$ \\
\hline $\begin{array}{l}\text { Item II: The length of time the medication } \\
\text { takes before relieving the pain }\end{array}$ & $5.1 \pm 1.1$ \\
\hline $\begin{array}{l}\text { Item 12: The amount of pain relief the } \\
\text { medication brings you }\end{array}$ & $5.5 \pm 0.8$ \\
\hline $\begin{array}{l}\text { Item 13: The duration of pain relief the } \\
\text { medication brings you }\end{array}$ & $5.2 \pm 0.9$ \\
\hline Overall mean & $4.9 \pm 0.7$ \\
\hline
\end{tabular}

Note: Results on a 6-point Likert-type scale for item importance (minimum $=1$ : least important; maximum $=6$ : very important).

Abbreviation: SAP-S, Satisfaction of Adolescents with Postoperative pain management - idiopathic Scoliosis.

until it is relieved" (5.5 \pm 0.8$)$. Only one item was considered slightly less important than others by participants, which was item 3 "The information about the way to measure pain with

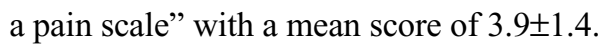

\section{Clinical outcomes: side effects, format of the medication and pain intensity}

Constipation/abdominal pain was the most frequently reported side effect $(72.5 \%)$ with a mean of 5.0/10 $( \pm 3.0)$ for unpleasantness, followed by dizziness $(62.3 \%)$ with a mean of $4.3 / 10( \pm 2.9)$.

Of the four medication administration routes most commonly used (oral, patch, rectal, patient-controlled analgesia), patient-controlled analgesia was the route with the highest satisfaction (mean of 5.0 \pm 1.3 ), whereas the rectal route had

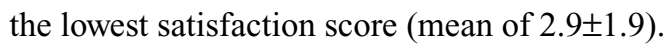

Participants' pain intensity varied between mild and moderate with a mean of $2.4( \pm 1.8)$ for the current level of pain and a mean of $5.0( \pm 2.5)$ for the worst pain experienced in the previous week. 


\section{Discussion}

The aim of this study was to determine the psychometric properties of the satisfaction subscale of the SAP-S scale (English version) with adolescents following spinal fusion for idiopathic scoliosis. Similar to the French version, PCA revealed a three-factor structure of the satisfaction subscale of the SAP-S scale. The initial French version of the SAP-S also had a three-factor solution (Ballard et al, unpublished data, 2016). However, the number of items per factor differed, from the French to the English version, with four items for Factor 1 instead of five and six items for Factor 2 instead of five. All items loaded on either one of the three factors with the exception of item 2 (satisfaction with "the information about medication used to reduce pain"), which loaded on Factor 3 nearly as much as it did on Factor 1. Based on the content and because it is recommended to have at least three items per factor to generate enough variances, ${ }^{29}$ it was decided to move Item 2 to Factor 3. Nevertheless, since we obtained a high Cronbach's alpha for the entire scale, it is questionable to have a three-factor structure. Further validation of the scale, with a larger sample, would help confirm or not a definite factorial structure.

Usually, Cronbach's alpha values between 0.70 and 0.95 are deemed acceptable. ${ }^{30}$ While some authors have raised concerns of redundancy with high values of alpha $(>0.90),{ }^{30}$ Bland and Altman ${ }^{31}$ recommended higher values up to 0.95 , especially if the scale is to be used in clinical application. Our analysis showed excellent internal consistency with a Cronbach's alpha of 0.91 using the 13-item satisfaction subscale of the SAP-S, suggesting appropriate use for clinical application. The highly correlated items suggest that all items measure the same construct, ${ }^{30}$ which, in this case, is the "satisfaction with postoperative pain management". Participants rated all 13 items to be important to very important; thus, no items were removed. In fact, as mentioned earlier, only one item (item 2) could have yielded a slightly higher Cronbach's alpha of 0.911 if deleted, but we decided not to remove the item due to rated importance by the participants (mean 4.29 \pm 1.433 ).

Interestingly, the items that were deemed the most important by patients were all related to the factor "Actions taken by nurses and doctors for pain management", especially helping the patient find a comfortable position in bed and believing them when they talked about their pain. This result reflects the important role of health care professionals in postoperative pain management that goes beyond the simple act of medication administration and concerns education and validation of the patient's pain experience.
Finally, the sample size was 82 participants from various cities and provinces across Canada. In addition, as the environment may differ from one center and one province to another, such a multicenter validation provides greater generalizability power. ${ }^{32}$ However, some authors would suggest that a sample size of at least 200-300 patients is often required to be able to generalize results. ${ }^{27,33}$

Furthermore, although the SAP-S scale was developed for adolescents who had undergone spinal fusion surgery, it can nonetheless be administered to adolescents from other surgical areas, as the items of the scale are not specific to post-spinal fusion but rather transferable to many postoperative pain management contexts. However, if the scale is to be used in a different cultural context, it is recommended that an adaptation and validation study be conducted with the new population.

\section{Conclusion}

To our knowledge, the SAP-S is the first scale to specifically assess adolescents' satisfaction with postoperative pain management. It can be used for both research and clinical purposes, and as such is a measure of great importance to keep health care professionals aware of the quality of pain care provided and to keep increasing the efforts toward improvement in pain management practices in surgical areas.

\section{Acknowledgments}

The authors (CK, SLM, AB, JT, and JMC) are members of Pain in Child Health, a strategic research training initiative of the Canadian Institutes of Health Research. This study was supported by a grant from the Fondation de Recherche en Sciences Infirmières du Québec (FRESIQ).

\section{Disclosure}

The authors report no conflicts of interest in this work.

\section{References}

1. Wright JG, Menaker RJ; Canadian Paediatric Surgical Wait Times Study Group. Waiting for children's surgery in Canada: the Canadian Paediatric Surgical Wait Times project. CMAJ. 2011;183(9):E559-E564.

2. Tzong KY, Han S, Roh A, Ing C. Epidemiology of pediatric surgical admissions in US children: data from the HCUP kids inpatient database. J Neurosurg Anesthesiol. 2012;24(4):391-395.

3. Tanner S. Trends in children's surgery in England. Arch Dis Child. 2007;92(8):664-667.

4. Erskine A, Wiffen PJ, Conlon JA. As required versus fixed schedule analgesic administration for postoperative pain in children. Cochrane Database Syst Rev. 2015;2:CD011404.

5. Rodrigues JB, Saleme NA, Batista JL Jr, Cardoso IM, Jacob C Jr. Quality of life in patients submitted to surgical treatment of idiopathic scoliosis. Acta Ortop Bras. 2015;23(6):287-289.

6. Borgeat A, Blumenthal S. Postoperative pain management following scoliosis surgery. Curr Opin Anaesthesiol. 2008;21(3):313-316. 
7. Bray L, Craske J. Idiopathic scoliosis: managing pain before and after spinal surgery. Nurs Child Young People. 2015;27(10):22-25.

8. Fortier MA, Chou J, Maurer EL, Kain ZN. Acute to chronic postoperative pain in children: preliminary findings. $J$ Pediatr Surg. 2011;46(9):1700-1705.

9. Joshi GP, Ogunnaike BO. Consequences of inadequate postoperative pain relief and chronic persistent postoperative pain. Anesthesiol Clin North America. 2005;23(1):21-36.

10. Ferland CE, Saran N, Valois T, et al. Preoperative distress factors predicting postoperative pain in adolescents undergoing surgery: a preliminary study. J Pediatr Health Care. Epub 2016 Feb 3.

11. Carr DB, Goudas LC. Acute pain. Lancet. 1999;353(9169):2051-2058.

12. Hamers JP, Abu-Saad HH. Children's pain at home following (adeno) tonsillectomy. Eur J Pain. 2002;6(3):213-219.

13. Sieberg CB, Simons LE, Edelstein MR, et al. Pain prevalence and trajectories following pediatric spinal fusion surgery. J Pain. 2013;14(12): 1694-1702.

14. Brasher C, Gafsous B, Dugue S, et al. Postoperative pain management in children and infants: an update. Paediatr Drugs. 2014;16(2): 129-140.

15. Wong GTC, Yuen VMY, Chow BFM, Irwin MG. Persistent pain in patients following scoliosis surgery. Eur Spine J. 2007;16(10):1551-1556.

16. Boulding W, Glickman SW, Manary MP, Schulman KA, Staelin R. Relationship between patient satisfaction with inpatient care and hospital readmission within 30 days. Am J Manag Care. 2011;17(1): $41-48$.

17. Wen J, Schulman KA. Can team-based care improve patient satisfaction? A systematic review of randomized controlled trials. PLoS One 2014;9(7):e100603.

18. Prakash B. Patient satisfaction. J Cutan Aesthet Surg. 2010;3(3):151-155.

19. Shirley ED, Sanders JO. Patient satisfaction: implications and predictors of success. Bone Joint J. 2013;95(10):e69.

20. Agency for Healthcare Research and Quality. Acute Pain Management in Infants, Children, and Adolescents: Operative Procedures. AHCPR Quick Reference Guides. Vol. 1b. Rockville, MD: Agency for Health Care Policy and Research (US); 1993.
21. Bhakta HC, Marco CA. Pain management: association with patient satisfaction among emergency department patients. J Emerg Med. 2014;46(4):456-464.

22. Hanna MN, Gonzalez-Fernandez M, Barrett AD, Williams KA, Pronovost P. Does patient perception of pain control affect patient satisfaction across surgical units in a tertiary teaching hospital? Am J Med Qual. 2012;27(5):411-416.

23. Manary MP, Boulding W, Staelin R, Glickman SW. The patient experience and health outcomes. N Engl J Med. 2013;368(3):201-203.

24. Scoliosis Research Society [webpage on the Internet]. Patient Outcome Questionnaires: SRS 30 Questionnaire. 2009. Available from: http:// www.srs.org/professionals/online-education-and-resources/patientoutcome-questionnaires. Accessed August 30, 2016.

25. Apfelbaum JL, Chen C, Mehta SS, Gan TJ. Postoperative pain experience: results from a national survey suggest postoperative pain continues to be undermanaged. Anesth Analg. 2003;97(2):534-540.

26. Le May S, Charette S, Chorney J, et al. Adolescents' pain management satisfaction after scoliosis repair surgery [workshop]. Scale presented at the International Symposium on Pediatric Pain; May 31-June 5; 2015; Seattle, WA, USA.

27. DeVellis RF. Scale Development: Theory and Applications. Vol. 26. Thousand Oaks, CA: SAGE Publications; 2016.

28. Nunnally JC, Bernstein I. The assessment of reliability. Psychometric Theory. 1994;3(1):248-292.

29. Hair J, Black W, Babin B, Anderson R. Multivariate Data Analysis. 7th ed. Upper Saddle River, NJ: Pearson Prentice Hall; 2010.

30. Tavakol M, Dennick R. Making sense of Cronbach's alpha. Int J Med Educ. 2011;2:53.

31. Bland JM, Altman DG. Cronbach's alpha. BMJ. 1997;314(7080):572.

32. Sprague S, Matta JM, Bhandari M, et al; Anterior Total Hip Arthroplasty Collaborative (ATHAC) Investigators. Multicenter collaboration in observational research: improving generalizability and efficiency. Bone Joint J. 2009;91(Suppl 3):80-86.

33. Streiner DL, Norman GR, Cairney J. Health Measurement Scales: A Practical Guide to Their Development and Use. USA: Oxford University Press; 2014.

\section{Journal of Pain Research}

\section{Publish your work in this journal}

The Journal of Pain Research is an international, peer reviewed, open access, online journal that welcomes laboratory and clinical findings in the fields of pain research and the prevention and management of pain. Original research, reviews, symposium reports, hypothesis formation and commentaries are all considered for publication.

\section{Dovepress}

The manuscript management system is completely online and includes a very quick and fair peer-review system, which is all easy to use. Visit http://www.dovepress.com/testimonials.php to read real quotes from published authors. 